\title{
The Optimum Analysis of Tapping Screw Subcontract Factories' Manufacturing Qualities with Taguchi Method
}

\author{
Chih-Cheng Yang, Wen-Ching Chao \\ Department of Mechanical and Automation Engineering, Kao Yuan University \\ 1821 Chung-Shan Road, Lu-Chu, Kaohsiung 82151, Taiwan \\ t30043@cc.kyu.edu.tw; simon@tycons.com
}

\begin{abstract}
The tapping screw is a well-developed, widely used fastener. The manufacturing processes of tapping screws are sequentially wire-manufacturing, forming (heading and threading), carburizing heat treatment, and phosphate coating, which can be conducted by subcontract factories. However, the manufacturing qualities of subcontract factories are sometimes uneven and resulting in difference in quality of products. The performance qualities of tapping screws are affected by the manufacturing qualities of subcontract factories. In this study, to improve the quality of AISI 1018 low carbon steel tapping screws, Taguchi method is used to evaluate the manufacturing qualities of subcontract factories. The quality characteristics of tapping screws, such as case hardness, core hardness, torsional strength, and drilling time, are investigated. The most important quality characteristic of a tapping screw is the drilling performance. It is experimentally revealed that the heat treating process $(\mathrm{H})$ and the coating process $(\mathrm{C})$ are the significant processes; while the forming process (F) and the wire manufacturing (W) are relatively not significant since they are well-developed manufacturing processes for tapping screws. Subsequently, the determined subcontract factories: W2, F2, H3 together with C2, evidently improve the performance measures. The drilling performance of the AISI 1018 tapping screws is effectively improved.
\end{abstract}

Keywords: tapping screw, subcontract factory, manufacturing quality, Taguchi method, drilling performance

\section{Introduction}

The goal of the manufacturing enterprise is to provide the best product at a lower price and with the lowest operating cost. Cost must be reduced without sacrificing the technical superiority of products [1]. The manufacturing processes of fasteners generally include wire-manufacturing, forming, heat treating, coating, and packing. Many well-developed fastener products, for cost reduction and work division, are usually fabricated by subcontract factories, such as wiremanufacturers, forming factories, heat treating factories, and coating factories. The tapping screw, as shown in Figure 1, is a well-developed, widely used fastener. The manufacturing processes of tapping screws are sequentially wiremanufacturing, forming (heading and threading), carburizing heat treatment, and phosphate coating, which can be conducted by subcontract factories.

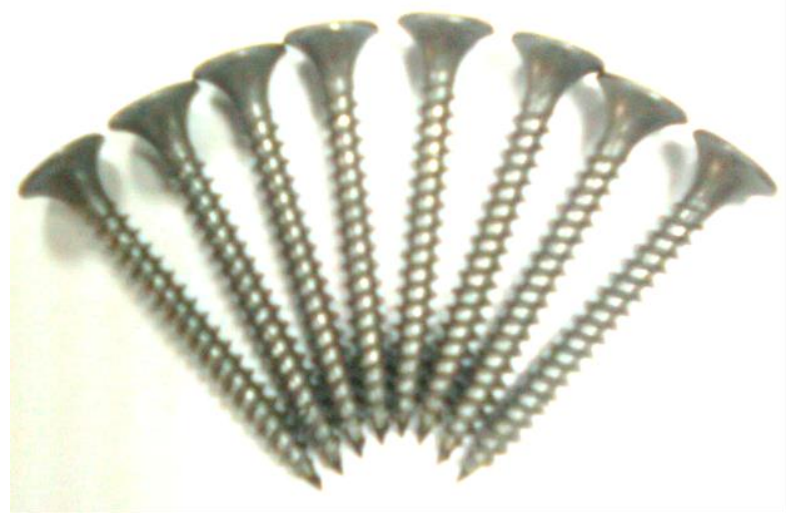

Fig. 1: Tapping screws. 
For wire-manufacturing, a cold-heading-quality alloy steel rod is used to manufacture wire for cold heading. Generally, the wire made from the quality rod is spheroidizing annealed, either in a single process or after drawing the finished product [2]. The wire is produced by drawing wire coil into wire, followed by heat treatment, cleaning and coating, and a final drawing operation for cold forming. Most wire-manufacturers use subcritical process for spheroidized annealing. The quality of wire-manufacturing affects the forming quality of screws. Taguchi method may be used to obtain the optimum quality of low carbon steel wire [3].

For forming process, cold forging is often applied in the fastener industry. Cold forging is performed at room temperature and is used to achieve better tolerance, higher mechanical properties, and a better surface aspect that can avoid further machining [4]. Cold heading is a forming process of increasing the sectional area of a billet at one or more points along its length. Along with the heading process, cold-headed parts may also undergo thread rolling [2]. The level of quality is due to the well mechanical properties of cold-headed parts, an uninterrupted fiber flow, close tolerances and a good surface quality. The cost benefit achieved using forging techniques is considerable.

In order to readily fabricate into tapping screws, low-carbon steel wire is usually used. To increase the strength of screws in self-drilling operation, a case-hardening treatment is usually an essential process. Gas carburizing is a casehardening process in which carbon is dissolved in the surface layers of a low-carbon steel part at a temperature sufficient to render the steel austenitic, followed by quenching and tempering to form a martensitic microstructure [5]. The resulting gradient in carbon content below the surface of the screws causes a gradient in hardness, producing a strong, wear-resistant surface layer on the material. The successful operation of the gas carburizing process depends on the control of various principal variables, such as temperature, time and atmosphere composition, which is usually conducted in a continuous carburizing furnace.

Phosphating is a widely used method of reducing wear on machine elements [6]. Zinc phosphate is usually used to treat forged steel screws to increase wear resistance and corrosion protection. Screws are coated in tumbling barrels immersed in phosphating solution. Coatings can be produced with a wide range of thicknesses, depending on the method of cleaning before treatment, composition of the phosphating solution, temperature, and duration of treatment.

The manufacturing qualities of subcontract factories are sometimes uneven and resulting in difference in quality of products, even producing poor-quality products. Therefore, it is important to evaluate the subcontract factories. Taguchi method is a quality improvement technique that uses experimental design methods for efficient characterization of a product or process, combined with a statistical analysis of its variability with the fact that preproduction experiments, properly designed and analyzed, can significantly contribute to efforts towards the accurate characterization and optimization of industrial processes, the quality improvement of products, and the reduction of costs and waste [7]. In this study, to improve the quality of tapping screws, Taguchi method is used to evaluate the manufacturing qualities of subcontract factories.

\section{Experiment Design}

AISI 1018 low carbon steel tapping screws are investigated in this study. Four manufacturing processes with three subcontract factories listed in Table 1 are selected as the experimental factors. Every process has three subcontract factories to evaluate the manufacturing qualities of tapping screws.

Table 1: Experimental factors and their subcontract factories for $\mathrm{L}_{9}$ orthogonal array.

\begin{tabular}{|l|c|c|c|}
\hline \multicolumn{1}{|c|}{ Factor (process) } & \multicolumn{3}{|c|}{ Subcontract factory } \\
\hline W: Wire manufacture & W1 & W2 & W3 \\
\hline F: Forming process & F1 & F2 & F3 \\
\hline H: Heat treatment & H1 & H2 & H3 \\
\hline C: Coating process & C1 & C2 & C3 \\
\hline
\end{tabular}

Taguchi method allows the changing of many factors at the same time in a systematic way, ensuring the reliable and independent study of the factors' effects. The orthogonal array table, $\mathrm{L}_{9}\left(3^{4}\right)$, is used as an experimental design for these four factors [8], as listed in Table 2. 
Table 2: $\mathrm{L}_{9}\left(3^{4}\right)$ orthogonal array experimental parameter assignment.

\begin{tabular}{|c|c|c|c|c|}
\hline \multirow{2}{*}{$\begin{array}{c}\text { Exp. } \\
\text { No. }\end{array}$} & \multicolumn{4}{|c|}{ Subcontract factory } \\
\cline { 2 - 5 } & Wire manufacture & $\begin{array}{c}F: \\
\text { Forming process }\end{array}$ & $\begin{array}{c}H: \\
\text { Heat treatment }\end{array}$ & $\begin{array}{c}C: \\
\text { Coating process }\end{array}$ \\
\hline $\boldsymbol{L} 2$ & W1 & F1 & H1 & C1 \\
\hline $\boldsymbol{L 3}$ & W1 & F2 & H2 & C2 \\
\hline $\boldsymbol{L 4}$ & W2 & F3 & H3 & C3 \\
\hline $\boldsymbol{L 5}$ & W2 & F2 & H2 & C3 \\
\hline $\boldsymbol{L 6} 6$ & W2 & F3 & H1 & C1 \\
\hline $\boldsymbol{L} 7$ & W3 & F1 & H3 & C2 \\
\hline $\boldsymbol{L} 8$ & W3 & F2 & H1 & C3 \\
\hline $\boldsymbol{L} 9$ & W3 & F3 & H2 & C1 \\
\hline
\end{tabular}

In this study, the quality characteristics of tapping screws, such as case hardness, core hardness, torsional strength, and drilling time, are investigated. As assigned by the company, the case hardness of a tapping screw is tested by a Vickers procedure with a specified range of 600-800 HV and the core hardness is with a specified range of 300-500 $\mathrm{HV}$. The minimum torsional strength of a tapping screw is $29 \mathrm{~kg} \cdot \mathrm{cm}$.

The most important quality characteristic of a tapping screw is the drilling performance, which is the ability of a screw to penetrate a piece of galvanised steel under controlled force and speed is measured. The tapping screw shall be, under controlled force of $12 \mathrm{~kg}$, penetrated a thickness of $0.7 \mathrm{~mm}$ steel plate not exceeding $1 \mathrm{sec}$, which is assigned by the company. Each test trial, including 10 specimens, is followed by each fabrication process and the results are then transformed to the $\mathrm{S} / \mathrm{N}$ ratio (signal-to-noise ratio). In terms of the desired characteristics for drilling time, the shorter the better, and the $\mathrm{S} / \mathrm{N}$ ratio is [8]

$$
\mathrm{S} / \mathrm{N}=-10 \cdot \log \left(\mu^{2}+S^{2}\right)
$$

where $\mu$ is the mean of each trial and $S$ is the standard deviation.

Analysis of variance (ANOVA) is an effective method to determine the significant factors and the optimal subcontract factories to obtain optimal quality. For Taguchi method, the experimental error is evaluated with ANOVA to carry out the significance test of the various factors. The nature of the interaction between factors is considered as experimental error [8]. If the effect of a factor in comparison to the experimental error is sufficiently large, it is identified as a significant factor.

\section{Results and Discussion}

The experiment results of case hardness, core hardness, torsional strength and drilling time (mean, $\mu$; standard deviation, $\mathrm{S}$; and $\mathrm{S} / \mathrm{N}$ ratio) are shown in Table 3. The means of case hardness vary from 664.6 to $727.2 \mathrm{HV}$, which are all within the specified range of 600-800 HV. The standard deviation of test L6 is the smallest of the nine tests, while the standard deviation of test L4 is the largest. For core hardness, the means vary from 419.0 to $468.6 \mathrm{HV}$, which are all within the specified range of 300-500 HV also. The standard deviations of tests L6 and L8 are respectively the smallest and the greatest. For torsional strength, the means of all nine tests are greater than the specified value (>29 $\mathrm{kg} \cdot \mathrm{cm})$, as shown in Table 3. These quality characteristics of tapping screws meet the requirement of specification. However, for the drilling performance test, the means of drilling time for tests L1 and L9 are exceeding $1 \mathrm{sec}$, which do not meet the specification. Especially for test L9, the mean drilling time of $1.670 \mathrm{sec}$ is too much, its standard deviation is the greatest and the S/N ratio is the smallest of the nine tests. The performance qualities of tapping screws are obviously affected by the manufacturing qualities of subcontract factories. 
Table 3: The experimental results for tapping screws.

\begin{tabular}{|c|c|c|c|c|c|c|c|c|c|}
\hline \multirow{2}{*}{$\begin{array}{c}\text { Exp. } \\
\text { No. }\end{array}$} & \multicolumn{2}{|c|}{ Case hardness } & \multicolumn{2}{c|}{ Core hardness } & Torsional strength & \multicolumn{3}{|c|}{ Drilling time } \\
\cline { 2 - 10 }$(\mathrm{HV})$ & $S$ & $\begin{array}{c}\mu \\
(\mathrm{HV})\end{array}$ & $S$ & $\begin{array}{c}\mu \\
(\mathrm{kg} \cdot \mathrm{cm})\end{array}$ & $S$ & $\begin{array}{c}\mu \\
(\mathrm{sec})\end{array}$ & $S$ & S/N ratio \\
\hline $\boldsymbol{L 1}$ & 671.4 & 20.7 & 441.8 & 21.4 & 39.2 & 1.30 & 1.120 & 0.336 & -1.359 \\
\hline $\boldsymbol{L 2}$ & 664.6 & 27.6 & 442.4 & 13.7 & 40.0 & 0.00 & 0.910 & 0.120 & 0.745 \\
\hline $\boldsymbol{L 3}$ & 717.0 & 18.7 & 445.0 & 15.7 & 40.4 & 0.89 & 0.850 & 0.108 & 1.342 \\
\hline $\boldsymbol{L 4}$ & 695.2 & 42.8 & 419.0 & 19.1 & 37.4 & 0.89 & 0.960 & 0.070 & 0.332 \\
\hline $\boldsymbol{L 5}$ & 722.4 & 12.2 & 441.4 & 17.3 & 38.2 & 0.84 & 0.880 & 0.114 & 1.039 \\
\hline $\boldsymbol{L 6}$ & 693.8 & 7.8 & 468.6 & 5.5 & 40.8 & 0.84 & 0.820 & 0.092 & 1.670 \\
\hline $\boldsymbol{L 7}$ & 727.2 & 12.5 & 420.4 & 23.3 & 40.0 & 0.00 & 0.760 & 0.097 & 2.314 \\
\hline $\boldsymbol{L 8}$ & 680.8 & 13.6 & 441.2 & 23.5 & 38.4 & 0.55 & 0.880 & 0.079 & 1.076 \\
\hline $\boldsymbol{L 9}$ & 666.2 & 14.3 & 437.6 & 5.6 & 38.2 & 0.84 & 1.670 & 0.657 & -5.079 \\
\hline Ave. & 693.2 & 18.9 & 439.7 & 16.1 & 39.2 & 0.68 & 0.983 & 0.186 & 0.231 \\
\hline
\end{tabular}

\subsection{Drilling time}

To obtain optimum quality, analysis of variance (ANOVA) is an effective method to determine significant factors and optimum subcontract factories. The contribution of each factor constructed in Table 4 could identify the significant factor affecting the performance quality of tapping screws. The contribution of a factor is the percentage of the sum of squares $(S S)$, that is, the percentage of the factor variance to the total quality loss [7,8]. It is clear from the ANOVA table that the contribution of coating process (C) is $48.0 \%$ of the total variation, which is the highest contributor to the variability of the experimental results. The contribution of heat treating process $(\mathrm{H})$ is $32.1 \%$, which is the second highest contribution. However, the factors of the forming process (F) and wire manufacture (W) are not significant for the $\mathrm{S} / \mathrm{N}$ ratio because their contributions are relatively small.

Table 4: Variance analysis table of $\mathrm{S} / \mathrm{N}$ ratios for drilling time.

\begin{tabular}{|l|c|c|c|c|}
\hline \multicolumn{1}{|c|}{ Factor } & \multicolumn{1}{c|}{$S S$} & DOF & Var & Contribution \\
\hline W (Wire manufacture) & 3.73 & 2 & 1.86 & $9.3 \%$ \\
\hline F (Forming process) & 4.22 & 2 & 2.11 & $10.6 \%$ \\
\hline H (Heat treatment) & 12.85 & 2 & 6.42 & $32.1 \%$ \\
\hline C (Coating process) & 19.21 & 2 & 9.60 & $48.0 \%$ \\
\hline \multicolumn{1}{|c|}{ Total } & 40.00 & 8 & & $100.0 \%$ \\
\hline
\end{tabular}

SS: sum of square; DOF: degree of freedom; Var: variance.

Figure 2 illustrates the factor response diagram and the level averages of four factors with respect to the $\mathrm{S} / \mathrm{N}$ ratio for drilling time. For each factor, the effect is the range of the level averages and the maximum level average is the optimum level $[7,8]$. For the significant factors of coating process $(\mathrm{C})$ and heat treatment $(\mathrm{H})$, subcontract factory $\mathrm{C} 2$ for the coating process and subcontract factory $\mathrm{H} 3$ for the heat treatmebt are evidently the optimum subcontract factories, as shown in Figure 2. The effects of the other two processes, the forming process (F) and the wire process (W), are relatively small since they are well-developed manufacturing processes for tapping screws. The optimum subcontract factories are $\mathrm{F} 2$ for the forming process and $\mathrm{W} 2$ for the wire process, respectively. 


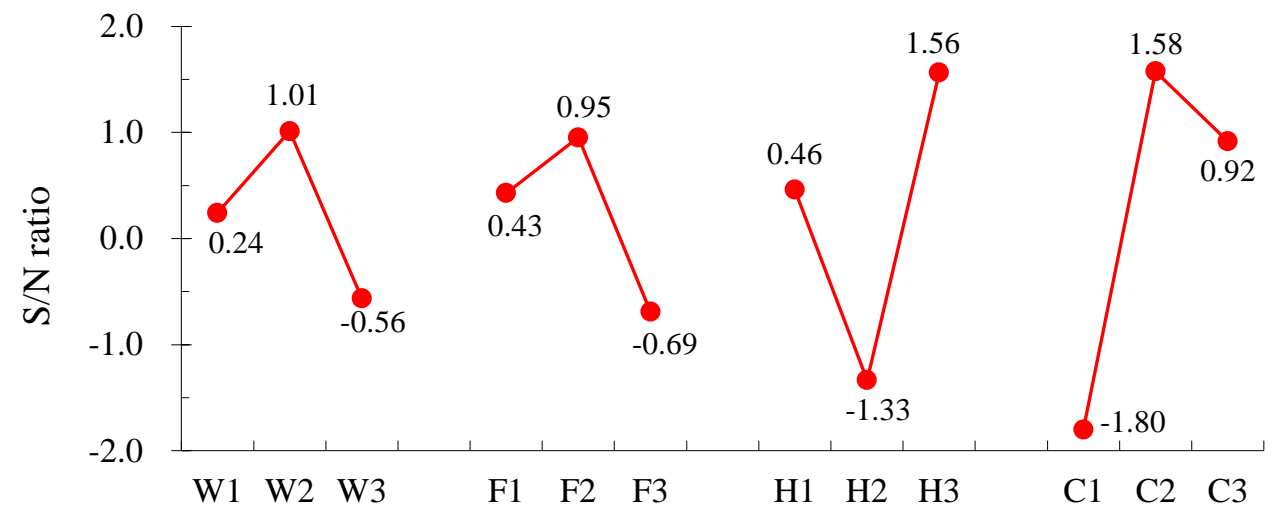

Fig. 2: The factor response diagram of $\mathrm{S} / \mathrm{N}$ ratios for drilling time.

\subsection{Confirmatory Experiments}

In order to verify the predicted results, tapping screws are fabricated with the optimum subcontract factories: W2, F2, $\mathrm{H} 3$ and $\mathrm{C} 2$ (as described in Figure 2). Variation is the inability to perform a task consistently according to a specification [1]. Figure 3 shows the natural variation of the process (6 process standard deviations, 6S [1]) of the nine tests and confirmatory experiment (optimum), including the given specification spans, for the case and core hardness of tapping screws; and Figure 4 is shown for the torsional strength together with drilling time of tapping screws, also including the given specification limits.

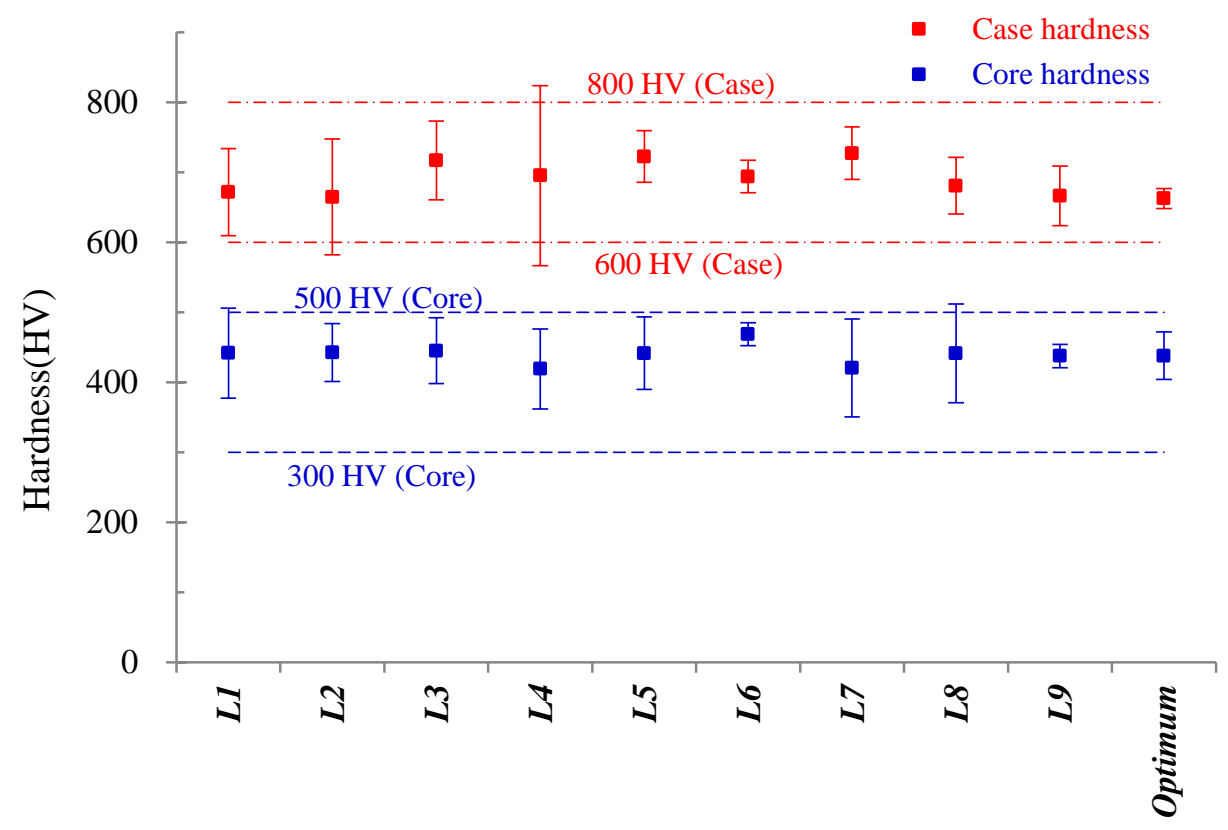

Fig. 3: The natural variation of the process $(6 S)$ for the case and core hardness.

Compared with the results of the nine tests, the optimum mean case hardness of $662.4 \mathrm{HV}$ is smaller than the averaged value (693.2 HV in Table 3), the natural variation of the process (6S) is obviously decreased and much smaller than the given tolerance band, as shown in Figure 3. The optimum mean core hardness of $437.8 \mathrm{HV}$ is decreased as well compared to the averaged value $(439.7 \mathrm{HV}$ in Table 3$)$ and the natural variation of the process $(6 \mathrm{~S})$ is also much smaller than the given tolerance band, as shown in Figure 3. This means that the process is capable of ensuring $99.73 \%$ of good products in hardness. 
For the torsional strength, as shown in Figure 4, the mean values of the nine tests are much greater than the lower specification limit. However, the optimum mean torsional strength of $35.2 \mathrm{~kg} \cdot \mathrm{cm}$ is smaller than the averaged value (39.2 $\mathrm{kg} \cdot \mathrm{cm}$ in Table 3), and the natural variation of the process $(6 \mathrm{~S})$ is still larger than the lower specification limit.

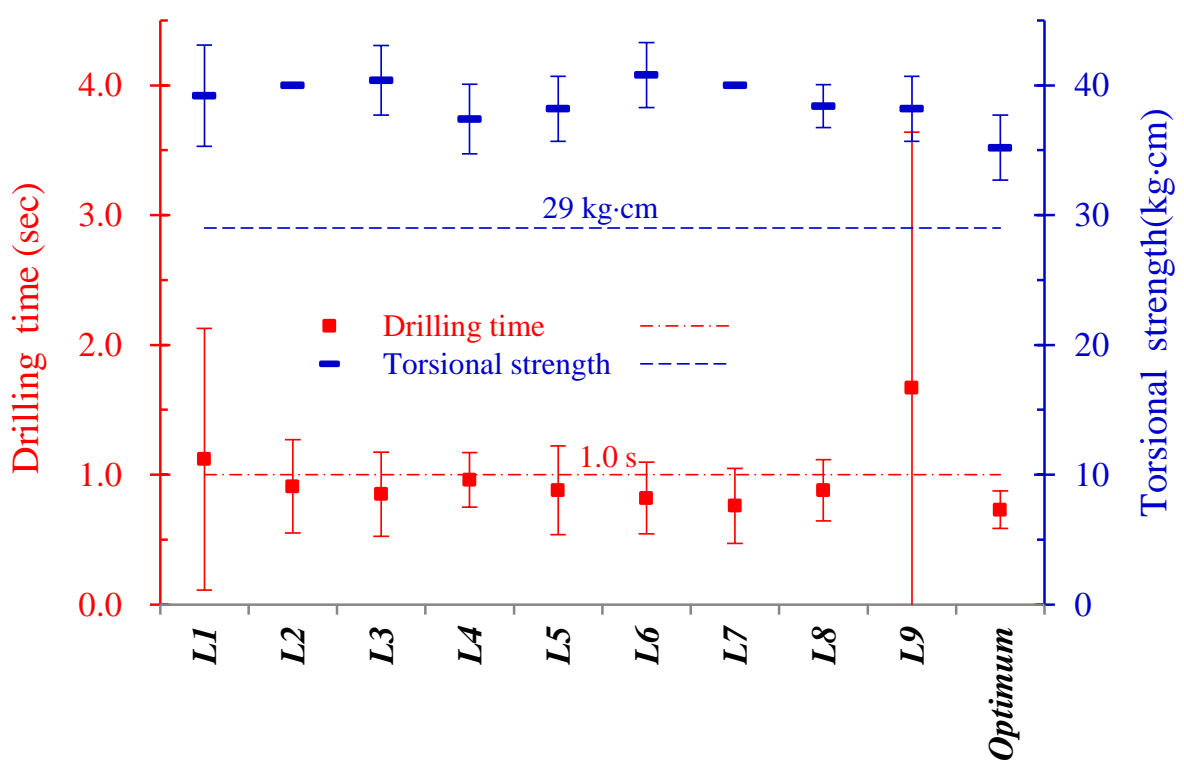

Fig. 4: The natural variation of the process $(6 S)$ for the torsional strength and drilling time.

Although the three quality characteristics of tapping screws almost meet the requirement of specification for the nine tests, the drilling performance is not good enough, as shown in Figure 4, because all the natural variations of the process $(6 S)$ are exceeding the upper specification limit for the drilling time. This means that the natural variations of the process $(6 S)$ are much larger than the specification limit given. Then, the process is incapable of ensuring $99.73 \%$ of good tapping screws [1]. However, the optimum mean drilling time of $0.73 \mathrm{sec}$ is not only smaller than the averaged value ( $0.983 \mathrm{sec}$ Table 3$)$; but also the natural variation of the process $(6 S)$ is obviously decreased and much smaller than the upper specification limit, as shown in Figure 4. Therefore, with the optimum subcontract factories: $\mathrm{W} 2, \mathrm{~F} 2, \mathrm{H} 3$ and C2, the process is capable of ensuring $99.73 \%$ of good tapping screws. That is, guarantee that only $2700 \mathrm{ppm}$ are expected to be defective.

\section{Conclusion}

The tapping screw is a well-developed, widely used fastener. The manufacturing processes of tapping screws are sequentially wire-manufacturing, forming (heading and threading), carburizing heat treatment, and phosphate coating, which can be conducted by subcontract factories. The manufacturing qualities of subcontract factories are sometimes uneven and resulting in difference in quality of products. The performance qualities of tapping screws are affected by the manufacturing qualities of subcontract factories. In this study, to improve the quality of AISI 1018 low carbon steel tapping screws, Taguchi method is used to evaluate the manufacturing qualities of subcontract factories. The quality characteristics of tapping screws, such as case hardness, core hardness, torsional strength, and drilling time, are investigated. As assigned by the company, the case hardness of a tapping screw is tested by a Vickers procedure with a specified range of 600-800 HV and the core hardness is with a specified range of 300-500 HV. The minimum torsional strength of a tapping screw is $29 \mathrm{~kg} \cdot \mathrm{cm}$. The most important quality characteristic of a tapping screw is the drilling performance. The tapping screw shall be, under controlled force of $12 \mathrm{~kg}$, penetrated a thickness of $0.7 \mathrm{~mm}$ steel plate not exceeding $1 \mathrm{sec}$.

It is experimentally revealed that the heat treating process $(\mathrm{H})$ and the coating process $(\mathrm{C})$ are the significant processes; while the forming process $(\mathrm{F})$ and the wire process $(\mathrm{W})$ are relatively not significant since they are welldeveloped manufacturing processes for tapping screws, which may be used to achieve the cost benefit. The determined 
subcontract factories are factory $\mathrm{H} 3$ for the heat treating process, factory $\mathrm{C} 2$ for the coating process, factory $\mathrm{F} 2$ for the forming process, and W2 for the wire process. In addition, the optimum drilling performance is $0.73 \mathrm{sec}$ mean drilling time which is much smaller than the upper specification limit, and so is the natural variation of the process; the process is capable of ensuring $99.73 \%$ of good tapping screws. Therefore, the determined subcontract factories: W2, F2, H3 together with C2, evidently improve the performance measures. The drilling performance of the AISI 1018 tapping screws is effectively improved.

\section{Acknowledgements}

The authors would like to acknowledge the support of TYCOONS Group Enterprise Co., Ltd., Kaohsiung, Taiwan, for providing the materials and apparatus to carry out the experimental works.

\section{References}

[1] P. F. Ostwald and J. Munoz, Manufacturing Processes and Systems, John Wiley \& Sons, USA, 1997.

[2] T. Padfield and M. Bhupatiraju, "Cold Heading," Metalworking: Bulk Forming, vol. 14A, ASM International: Materials Park, OH, USA, 2008.

[3] C.-C. Yang and C.-L. Liu, "Improvement of the Mechanical Properties of 1022 Carbon Steel Coil by Using the Taguchi Method to Optimize Spheroidized Annealing Conditions," Materials, vol. 9, no. 8, p. 693, 2016.

[4] R. H. Wagoner and J.-L. Chenot, Metal Forming Analysis, Cambridge University, UK, 2001.

[5] C. A. Stickels, "Gas Carburizing," Heat Treating, vol. 4, ASM International: Materials Park, OH, USA, 2011.

[6] A. Gibson, "Phosphate Coatings," Surface Engineering, vol. 5, ASM International: Materials Park, OH, USA, 2011.

[7] N. Logothetis, Managing for Total Quality: From Deming to Taguchi and SPC, Prentice Hall International: London, UK, 1992.

[8] H,-H, Lee, Taguchi Methods: Principles and Practices of Quality Design, Gau Lih Book Co. Ltd., Taiwan, 2008. 